\title{
Validation of the City Infant Faces Database in Student and Parent Samples
}

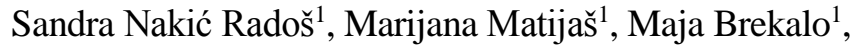 \\ Rebecca Webb², and Susan Ayers ${ }^{2}$ \\ ${ }^{1}$ Catholic University of Croatia, Department of Psychology, Zagreb, Croatia \\ ${ }^{2}$ City University of London, Centre for Maternal and Child Health Research, London, UK
}

\begin{abstract}
The City Infant Faces Database (CIFD; Webb et al., 2018) is a database of 154 infant emotional expressions for use in experimental studies of infant facial communication, facial expression recognition, and parental sensitivity. The CIFD was validated only in a small sample from the general public and student midwives and nurses in the UK. This study, therefore, aimed to validate it in a larger sample of Croatian students and parents of 1-12 months old infants. Three-hundred and fifty students (Study 1), 422 mothers and 106 fathers (Study 2) were presented with images of Caucasian infant faces. The students rated images from the CIFD and Tromsø Infant Faces. They also completed questionnaires measuring empathy, alexithymia, and perceiving and expressing emotions. The parents rated the valence of facial expressions of images from the CIFD. The results were consistent with the initial validation in both the students and parents' sample, except that agreement for negative images was lower for Croatian parents than in the UK study. Compared to the UK study, students rated images as more intense, clear, genuine, and reported stronger internal emotion. Furthermore, there was no difference in accuracy between mothers and fathers or between first-time parents and experienced parents. The CIFD is, therefore, a promising tool for research and should be further validated in other countries, focusing on its predictive validity.
\end{abstract}

Keywords: infant, facial expression, validation, database, parents

Sandra Nakić Radoš, Department of Psychology, Catholic University of Croatia, Ilica 242, 10000 Zagreb, Croatia. E-mail: snrados@unicath.hr

This work was financed by the project of the Catholic University of Croatia "Parental mental health and contextual factors as determinants of parent-infant bonding", under Grant HKS-2018-4.

Sandra Nakić Radoš: https://orcid.org/0000-0002-8330-8427

Marijana Matijaš: https://orcid.org/0000-0003-2474-340X

Maja Brekalo: https://orcid.org/0000-0001-6766-5304

Rebecca Webb: https://orcid.org/0000-0002-8862-6491

Susan Ayers: https://orcid.org/0000-0002-6153-2460 


\section{Introduction}

Human facial emotional expressions are one of the mechanisms through which humans communicate with one another. Darwin (1872) was the first to suggest that human facial expressions are biologically innate, have evolved, and play a useful function in survival. Darwin used evidence of globally observed and recognised facial expressions to support this theory. Since the publication of Darwin's theory, much research has provided supporting evidence for the universality of facial expressions following pioneer work by Ekman and colleagues (Ekman, 1972; Ekman \& Friesen, 1971; Ekman et al., 1987). These culturally universal expressions are happiness/joy, sadness, surprise, fear, disgust, and anger (Ekman \& Friesen, 1971).

The universal ability to demonstrate and recognise a facial emotional expression ensures survival even when one cannot speak. Human infants are born more immature than any other known species on the planet (Bjorklund, 1997; Montagu, 1961) and are therefore very reliant on others' understanding their cues to survive. There is some evidence to suggest that infants have an innate ability to express distress, interest, and enjoyment in their faces (Castanho \& Otta, 1999; Izard, 1971, 1994; Izard et al., 1980; Reissland et al., 2013; Yan et al., 2006). Evolutionary theories suggest that the development of infant facial expressions was designed by natural selection to communicate important information to the caretaker about the infant's emotional state (Babchuk et al., 1985). This arguably increases an infant's chances of survival.

It is crucial for infants' survival that parents correctly interpret their facial expressions. Infants showing positive facial expressions (e.g. happy face) are trying to communicate and engage their caregivers for what is necessary for their development. Conversely, by showing negative facial expressions (e.g. sad faces), they try to express unwanted experiences and engage caregivers to help them (Bolzani-Dinehart et al., 2005). In addition, parental inability to detect infant facial signals may lead to failure in responding or inappropriate responses to infant signals (Donovan et al., 2007). It is therefore important to be able to measure the recognition of infants' facial expressions accurately. Infant facial expression recognition is mostly measured in studies examining its neural basis (e.g. Nishitani et al., 2011), attentional processing in relation to parental mental health (e.g. Pearson et al., 2010; Tang et al., 2019; Webb \& Ayers, 2019) and mother-infant bonding (e.g. Nakić Radoš, 2021), or for detecting emotions using the machine learning techniques (e.g. Fahmy et al., 2020).

Although databases of adults' facial expressions have been developed since Ekman and Friesen's (1976) work on Pictures of Facial Affect (POFA), there are only a few validated databases of infants faces: the Chinese Infant Affective Face Picture System (Cheng et al., 2015), Infant Face Ratings Task (Arteche et al., 2016), Tromsø Infant Faces (Maack et al., 2017), City Infant Faces Database (Webb et al., 2018), and Baby Faces (Donadon et al., 2019). Furthermore, a few authors (e.g. 
Camras et al., 2007; Nishitani et al., 2011; Pearson et al., 2010) have designed sets of infant images for their research but have not validated them, so these are not included in the following overview.

Chinese Infant Affective Face Picture System (Cheng et al., 2015) comprises 317 images of infants 3-6 months old. The database provides only images of Chinese infants. These three emotional states are included: happy, neutral, and sad. Infant Face Ratings Task (Arteche et al., 2016) has 116 grayscale images of 4-12 months old infants. In this database, photos of 13 Brazilian infants (from different ethnicities) are merged with 27 infants from the Oxford Parent Project. Pictures of Brazilian infants were taken in natural settings, including their home, nursery and, in the case of one infant, in the university laboratory. Images were matched regarding size and luminosity. There are five emotion conditions: positive, muted positive, neutral, muted negative, and negative. Muted emotional expressions are those that are midway between neutral and positive/negative. Tromsø Infant Faces (TIF; Maack et al., 2017) comprises 119 colour images of 4-12 months old infants. All the infants are Caucasian, including ten girls and eight boys. All photos were taken in the same room with a white background, and the infants wore a white bodysuit and a white hat. This database has images with the broadest emotional range, i.e., seven emotional states: happy, sad, disgust, fear, anger, surprise or neutral. The City Infant Faces Database (CIFD; Webb et al., 2018) consists of 154 images of 1-12 months old infants (33 boys, 36 girls). Most infants are Caucasian, but there are three Asian, two Arab, and one Indian infant. Parents gathered all the images in natural settings. The instructions given by the researchers were that the photographs should be taken at the same time of the day, and the baby's head should be at the same angle for each picture. This is the only database that includes both black-and-white and colour images. The original backgrounds of the photos were photoshopped to replace different backgrounds in the photographs. The backgrounds were replaced with a blank white background on the colour images and a blank black background on the black-and-white photos. Three emotional states are included in the database: positive, neutral, and negative. Baby Faces (Donadon et al., 2019) contains 72 colour images of twelve infants (50\% girls) aged 6-12 months. One of the aims when creating this database was to include babies with greater racial diversity. Therefore, Caucasian, black, and Japanese babies were included in the database. Images were taken in the laboratory under controlled conditions of temperature, light, and noise. All photos were standardised by size, orientation, and background. Five basic emotions: happiness, sadness, surprise, fear, and anger and neutral are included.

From this overview, it is apparent that several features can distinguish these five infant face databases: (1) number of images, (2) infants' age range represented in the database, (3) racial and ethnic diversity of the stimulus faces, (4) the process of creating a set of images - natural or laboratory environment, (5) the complexity/number of emotional expressions that are evaluated, and (6) the colour of the images. The CIFD has several advantages over other databases. First, the CIFD 
is the only database that includes images of infants with a wide age range from 1 to 12 months. Second, it is the only database that includes both black-and-white and coloured images. Finally, the CIFD comprises images with racial and ethnic diversity, which can be important for conducting research in the multicultural surrounding. There are only three types of emotional expressions included (positive, neutral, and negative) in the CIFD. However, research has found that adults tend to blend the expressions for some emotions when rating infant faces, i.e., surprise and fear or sadness and anger (Maack et al., 2017; Sullivan, 2018; Sullivan \& Lewis, 2003). Therefore, the valence of emotion may be more appropriate when investigating recognition of infants' emotional expressions. The CIFD appears valid and reliable from the initial validation in a sample of student midwives and nurses and the general public $(n=71)$ where only images with at least $75 \%$ of rating agreement were retained (Webb et al., 2018).

Some individual differences could affect facial expression recognition. In this research, we focused on the relationships with alexithymia, empathy, and emotional competence. Alexithymia is a personality construct that involves reduced ability in identification and verbalization of emotions and externally oriented or concrete thinking style (Taylor et al., 1991). It is related to less accurate emotional recognition (e.g. Lane et al., 1996; Parker et al., 1993). However, some research did not find differences in recognition of facial expressions between alexithymic and nonalexithymic individuals (e.g. McDonald \& Prkachin, 1990). Donges et al. (2014) suggested that these inconsistent results are due to the modest effect size of the relationship between alexithymia and processing of facial emotion, which can be undetectable when the sample size is small. Furthermore, empathy could also be an important construct related to the recognition of emotional facial expressions. Two types of empathy can be distinguished: cognitive and emotional (Davis, 1983). Cognitive empathy represents understanding other people's thoughts, emotions and behaviour; and emotional empathy represents having an emotional response to others' emotional states (Besel \& Yuille, 2010). More is known about the relationship between emotional empathy and facial recognition compared with the relationship between cognitive empathy and facial expression. People with more emotional empathy are better at facial recognition (Besel \& Yuille, 2010; Gery et al., 2009). Finally, emotional competence refers to self-reported ability to perceive and understand emotions, express and label emotions, and regulate emotions (Takšić et al., 2006). Emotional competence is therefore likely to be correlated with recognition of facial expressions.

So far, the CIFD was validated on student midwives and nurses $(n=53)$ and a small sample from the general public $(n=18)$. Therefore, it needs further validation in a larger sample, including parents. Only a small portion of the colour images was validated in the UK (Webb et al., 2018), so we focused only on the black-and-white images. Thus, we were able to compare data from UK and Croatia. The initial development and validation were conducted only in the UK, so the use and validity 
of the CIFD in other countries needs examining. This is especially important because the CIFD is widely used internationally by researchers in 31 countries (Webb, 2021, personal communication). Therefore, this study aimed to validate the CIFD in large samples of students (Study 1) and parents (Study 2) and contribute to knowledge about the validity of the CIFD internationally by examining this in Croatia.

\section{Study 1}

\section{Method}

\section{Participants}

The sample of students included 426 participants from the Catholic University of Croatia. However, all those who were parents were excluded $(n=73)$, leaving the sample of 353 undergraduate and graduate students (77.1\% female). The students were studying psychology (47.3\%), history (17.3\%), and nursing (32.0\%) and ranged from 18 to 51 years old $(M=22.5$ years, $S D=4.58)$. Almost half were single $(50.4 \%), 42.8 \%$ were in a relationship, and a minority were married or cohabiting (3.1\%). Furthermore, $56.1 \%$ reported not having daily contact with children younger than three years, compared to $37.4 \%$ who did have this kind of contact.

\section{Instruments}

City Infant Faces Database (CIFD; Webb et al., 2018) consists of 154 blackand-white photographs of 34 female and 29 male infants from 1 to 12 months old. Infants show negative (depicted as sad, angry, worried, scared, or distressed), neutral or positive facial expression (described as smiling, laughing, or excited). All photographs in the original database were provided by parents who were approached through social media sites. Each parent was asked to provide multiple pictures of their infant showing at least one negative, neutral, and positive emotion. From this original set of images, we used only Caucasian infants because most citizens in Croatia are Caucasian. Therefore, in this research, we used 139 photographs showing 50 negative, 35 neutral, and 54 positive expressions. As in the original validation study (Webb et al., 2018), all the images were rated on the six dimensions: expression of the image (negative, neutral, positive), the intensity of the emotion $(1-$ weak, 5 strong), clarity of the expression (1 - unclear, 5 - clear $)$, genuineness of the expression ( 1 -fake, 5 - genuine), the affective response of participant while viewing the image (negative, neutral, and positive) and strength of the affective response $(1-$ weak, 5 - strong).

Tromsø Infant Faces Database (TIF; Maack et al., 2017) was used to measure the convergent validity of the CIFD. TIF consists of 119 colour images from 10 female and eight male Caucasian infants. Infants were aged 4 to 12 months old. Each image presented one emotion: happy, sad, disgust, fear, anger, surprise or neutral. In 
this study, participants were asked to choose which of the seven emotions best described the infant's emotional expression. We calculated accuracy for every participant by dividing the number of correct answers by the number of images shown to that participant (more information in the Procedure section). Therefore, results can range from $0-1$, where a higher score indicates greater accuracy.

The Emotional Empathy Scale (Raboteg-Šarić, 2002) was used to self-assess the tendency of a person to have an emotional reaction to the emotional state of others. Items describe experiencing emotions as a reaction to another person's emotional state, caring for the disadvantaged, and experiencing emotional arousal in response to another person's unpleasant experiences. The participant's task was to evaluate the 19 items on a scale from 0 (completely disagree) to 4 (completely agree). A higher average score indicates greater empathy. Cronbach's $\alpha$ coefficient in this research was high, $\alpha=.87$.

The Emotional Skills and Competence Questionnaire (ESCQ; Takšić et al., 2009) assesses what is often referred to as a personality trait of emotional intelligence. The questionnaire contains three subscales that measure the ability to Perceive and Understand Emotions (15 items), Express and Label Emotions (14 items), and Manage and Regulate Emotions (16 items). In this study, we used only the first two subscales. The participant's task was to evaluate how much each item related to them $(1-$ never, 5 -always). The results are formed for each subscale as a linear combination of items. Higher scores on the subscales indicate more emotional competence. Cronbach's $\alpha$ coefficients for both Perceive and Understand Emotion subscale and Express and Label Emotion subscale were high: $\alpha=.86$ and $\alpha=.85$, respectively.

Toronto Alexithymia Scale (TAS-20; Parker et al., 2003) was used to measure alexithymia as a deficiency in cognitive processing of emotions (Taylor et al., 1991). Alexithymia consists of an emotional component: deficits in identifying and describing one's feelings, and a cognitive component: a tendency for concrete thinking about external events rather than internal emotional experiences ( $\mathrm{Li}$ et al., 2015). Participants rated each of 20 items on a scale from 1 (strongly degree) to 5 (strongly agree), where higher scores indicate more pronounced alexithymia. The TAS consists of three subscales: Difficulty Identifying Feelings - DIF (7 items), Difficulty Describing Feelings - DDF (5 items), and Externally Oriented Thinking EOT ( 8 items). Cronbach's $\alpha$ coefficient of the total scale was high, $\alpha=.84$, and for DIF, DDF, and the EOT subscale was $.84, .79$ and .56 , respectively.

Finally, demographic data were collected about participants: age, gender, parental status (Do you have children? Yes/No) and contact with children younger than three years (not having daily contact/having daily contact). 


\section{Procedure}

The Ethics Committee of the Catholic University of Croatia approved the study. The research was conducted at the University in groups in a classroom before lectures. Participants were introduced to the aim of the project and signed a written consent form. Each participant then received a booklet with questions about images from two databases (CIFD and TIF) and a series of questionnaires. All photos from the CIFD and TIF databases were randomly distributed in four blocks. Participants saw images only from one of the blocks for both databases. Each participant rated 35 (blocks 1 3) or 34 (block 4) images from the CIFD database and 30 (blocks 1-3) or 29 (block 4) images from the TIF database. Thus, each image was rated by at least 60 participants. All images were $15.92 \times 11.58 \mathrm{~cm}$ (height x width) in Microsoft Office PowerPoint and were presented using the projector screen in the classroom. In the left upper corner of the screen, there was the number of the image so participants could match each image with the exact series of questions for each image in the booklet. Each image was presented for $15 \mathrm{~s}$, during which participants had to rate the image. Images were presented for 20s in the original study (Webb et al., 2018); however, our informal pilot study (not presented here) showed that $15 \mathrm{~s}$ per image is enough to take a good look at the photo and evaluate its facial expression. The participants were instructed to rate each photo immediately after seeing it because of the limited exposure time. In the beginning, participants had two practice trials, after which they could ask questions about the procedure. There was a blank untimed slide after six images to allow the participants enough time. After rating the infant facial expressions, participants completed the rest of the questionnaires. Participants needed approximately $25-30$ minutes to evaluate the CIFD, TIF and complete the questionnaires.

\section{Results}

The average percentage of raters' agreement on the valence of the emotion of the image was $85.84 \%$. More specifically, the level of agreement for positive, neutral, and negative emotional expressions was $86.02 \%, 80.27 \%$, and $89.53 \%$ respectively. Out of 139 images tested, 22 images had the level of agreement below $75 \%$.

A series of two-way ANOVAs showed that, on average, there was a significant effect of valence of emotion on the intensity $\left(F(2,136)=46.81, p<.001, \eta^{2}=.41\right)$, clarity $\left(F(2,136)=53.51, p<.001, \eta^{2}=.44\right)$, and genuineness ratings $(F(2,136)=$ $20.69, p<.001, \eta^{2}=.23$ ). Post hoc procedures showed that neutral images were rated as significantly less intense, less clear, and less genuine than negative and positive images. The same effect was also significant for the strength of internal emotion $(F(2$, 136) $=57.31, p<.001, \eta^{2}=.46$ ), with somewhat different pattern of results. Namely, the strength of internal emotion was the strongest for positive images $(M=3.44, S D=$ $0.03)$, then for negative images $(M=3.14, S D=0.04)$, and the least for neutral images $(M=2.87, S D=0.04)$. Descriptive statistics for intensity, clarity, genuineness, and strength of internal emotion by valence of the emotion are presented in the Table 1. 


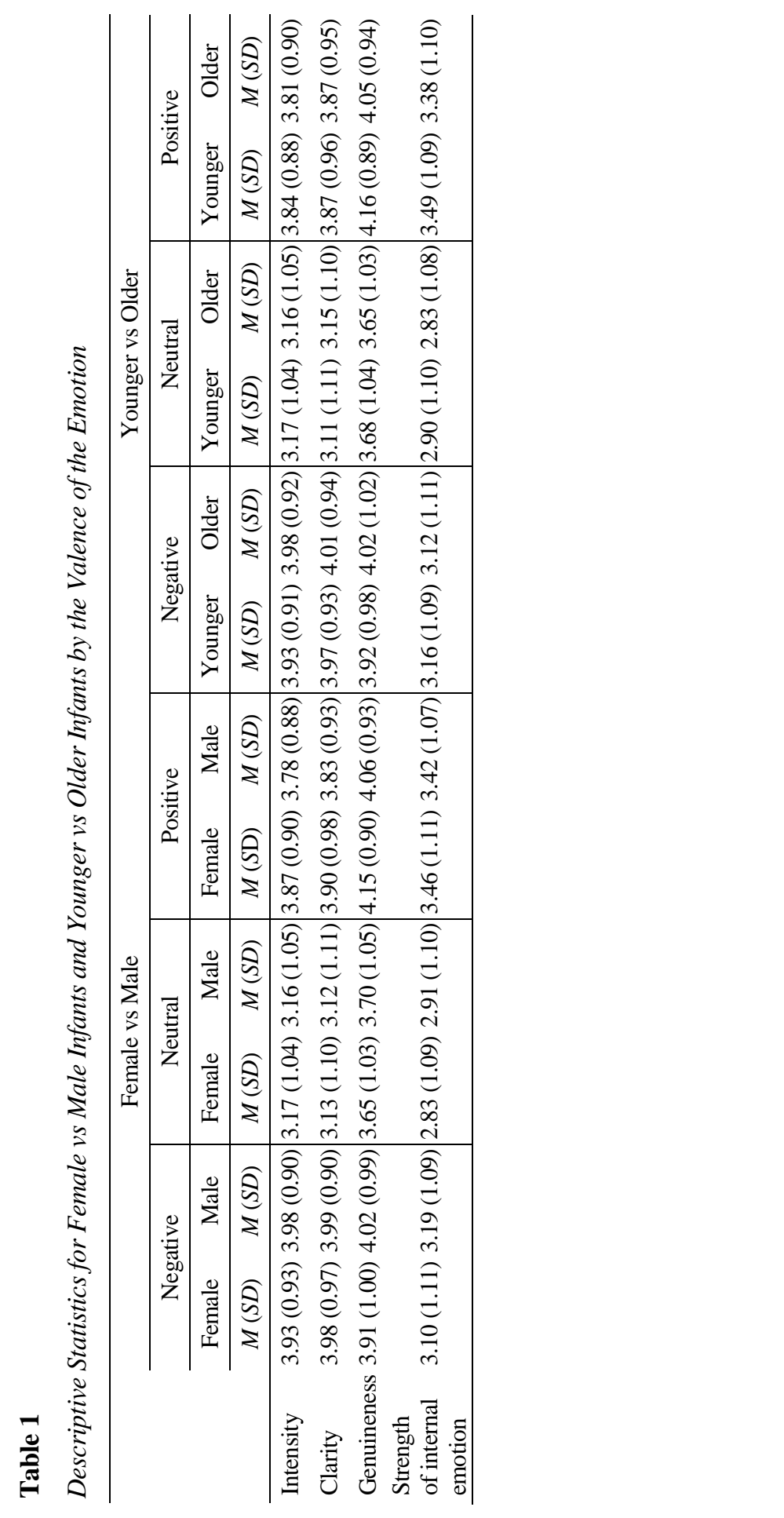




\section{Female versus Male Infants}

We used a two-proportion $z$-test $(z)$ to compare the accuracy of recognition based on infant gender. There was no difference in the level of agreement on the valence of the emotion in female versus male infants for negative $(z=0.04, p=.968)$, neutral $(z=-0.04, p=.968)$, and positive valence $(z=0.20, p=.842)$. Further analysis showed that there was no significant effect of infant gender on ratings of intensity $\left(F(1,133)=0.09, p=.760, \eta^{2}=.00\right)$, clarity $\left(F(1,133)=0.09, p=.765, \eta^{2}=.00\right)$, genuineness $\left(F(1,133)=0.24, p=.626, \eta^{2}=.00\right)$, or strength of the internal emotion $\left(F(1,133)=0.77, p=.383, \eta^{2}=.01\right)$ showing that images of female and male infants were rated as equally intense, clear, and genuine, and provoked equally strong emotions in the raters.

\section{Younger versus Older Infants}

There was no difference in the level of agreement (two-proportion $z$-test) on the valence of the emotion presented by younger versus older infants for negative ( $z=$ $0.05, p=.960)$, neutral $(z=0.05, p=.960)$, or positive valence $(z=-0.03, p=.976)$. Further analysis showed that there was no significant effect of infant age either on the intensity $\left(F(1,133)=0.00, p=.966, \eta^{2}=.00\right)$, clarity $(F(1,133)=0.13, p=.715$, $\left.\eta^{2}=.00\right)$, genuineness $\left(F(1,133)=0.02, p=.888, \eta^{2}=.00\right)$, or strength of internal emotion $\left(F(1,133)=2.70, p=.103, \eta^{2}=.02\right)$ showing that images of both younger and older infants were rated as equally intense, clear, and genuine, and provoked equally strong emotions in the raters.

\section{Convergent Validity}

The convergent validity of the CIFD was examined against Tromsø Infant Faces Database and the psychological questionnaires that measure the ability to identify and describe feelings (Table 2). The average percentage of accuracy of ratings for the Tromsø images was $60.24 \%$. Accuracy of ratings for CIFD images of different valences had a low and significant correlation with accuracy on Tromsø images (for total accuracy: $r=.36, p<.001$ ).

The accuracy of ratings for CIFD was related to scores on the psychological questionnaires. It showed that greater total accuracy on the CIFD was related to greater self-reported empathy $(r=.24, p<.001)$ and lower levels of alexithymia ( $r=-.15, p=.009$ ), specifically on the subscale of externally oriented thinking $(r=-.19, p=.001)$. Interestingly, this pattern was observed for accuracy on negative and positive images but not for neutral images. On the other hand, accuracy on the CIFD was not related to perceiving and describing emotions, either as measured by the Emotional Skills and Competence Questionnaire or Toronto Alexithymia Scale. The accuracy of ratings for Tromsø images correlated only with empathy $(r=.18$, $p=.001)$. 


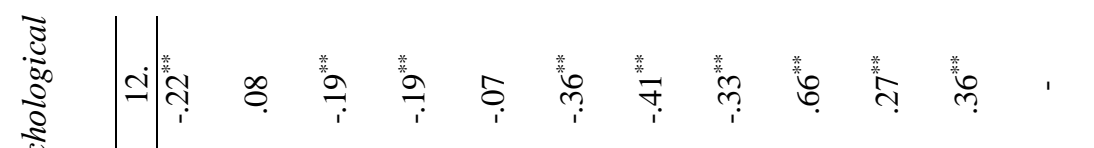

竞

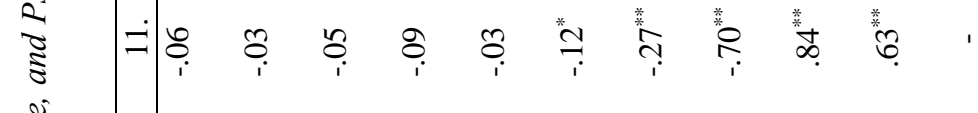

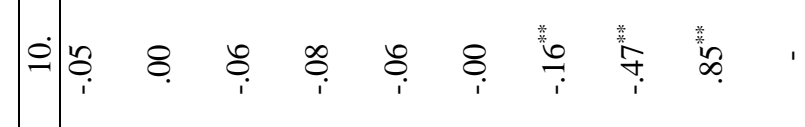

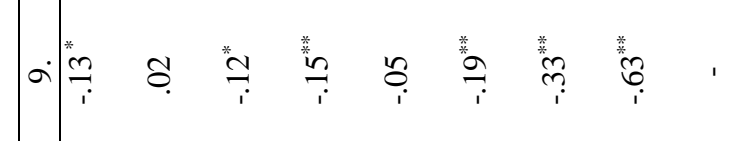

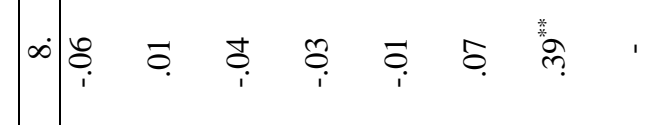

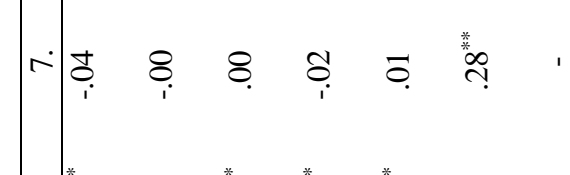

๑)

है

$\sqrt{2}$

吾

咅

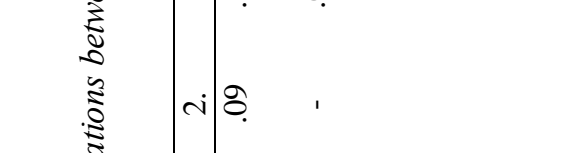
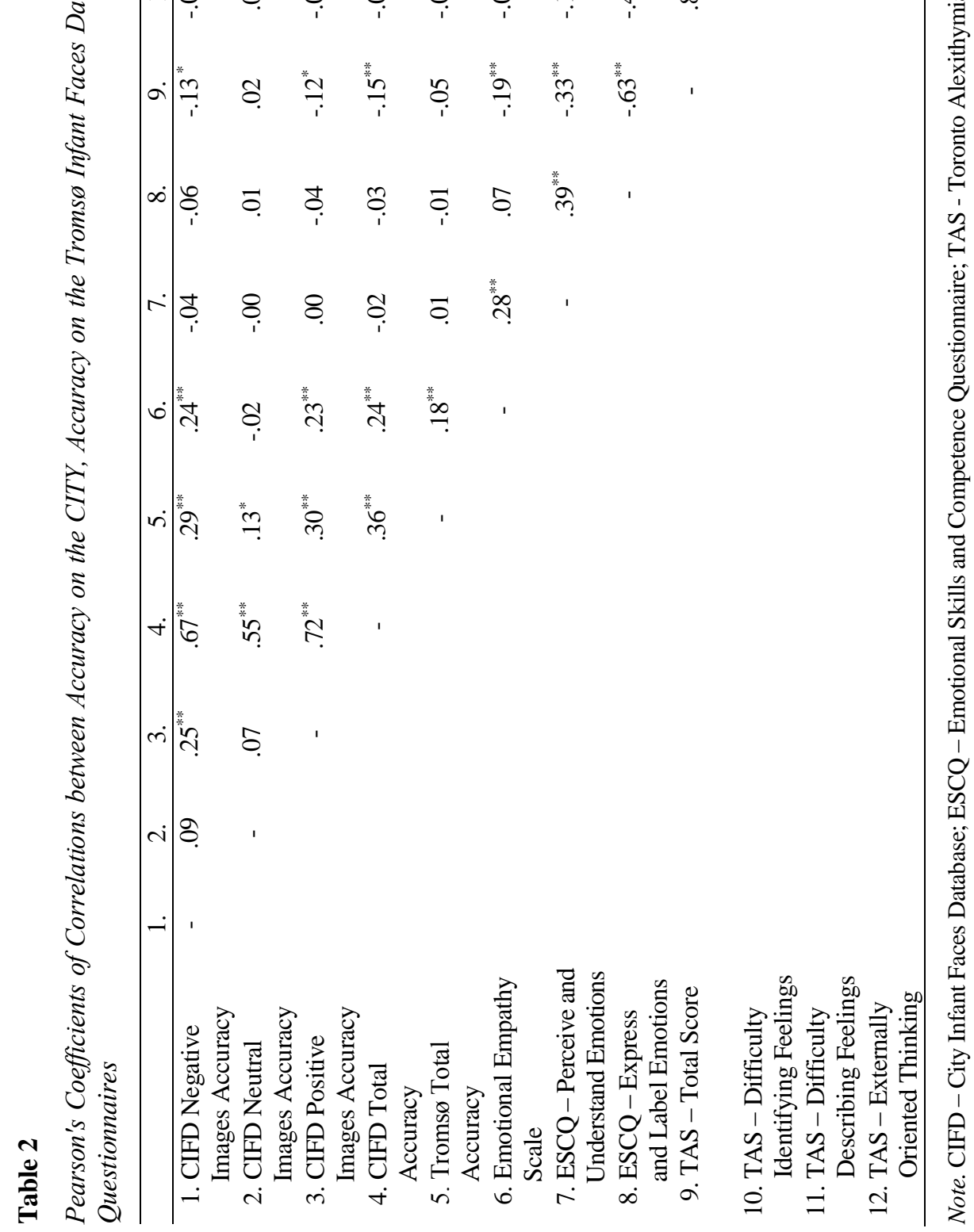


\section{Comparison between Croatian and UK Validation}

Compared to the original validation study in the UK (Webb et al., 2018, p. 154), data from the current study showed that Croatian raters, on average, reached the same rate of agreement as the UK raters (Table 3). Namely, raters from both countries had equal levels of agreement for negative $(z=1.02, p=.308)$, neutral $(z=0.51, p=$ $.610)$, and positive images $(z=1.82, p=.069)$, as tested by $z$-test for proportions.

Table 3

Descriptive Statistics for the Level of Agreement by the Valence of the Facial Expression

\begin{tabular}{lccc}
\hline Valence & No. images & Agreement $(\%)$ & $\begin{array}{c}\text { No. images with } \\
<75 \% \text { agreement }\end{array}$ \\
\hline Negative & 50 & 89.53 & 4 \\
Neutral & 35 & 80.27 & 9 \\
Positive & 54 & 86.02 & 9 \\
Total & $139(90 \%)$ & 85.84 & 22 images \\
\hline
\end{tabular}

Compared to the original validation study in the UK (Webb et al., 2018, p. 156), data from the current study showed that Croatian participants rated images as being more intense $\left(F(1,136)=143.59, p<.001, \eta^{2}=.51\right)$, more clear $(F(1,136)=76.63$, $\left.p<.001, \eta^{2}=.36\right)$, more genuine $\left(F(1,136)=56.74, p<.001, \eta^{2}=.29\right)$, and as provoking stronger internal emotion $\left(F(1,136)=156.68, p<.001, \eta^{2}=.54\right)$ (Table 4). These effects were present for negative, neutral, and positive images. However, there was a significant interaction between the source of the data and valence of the images for clarity $\left(F(2,136)=5.37, p=.006, \eta^{2}=.07\right)$ and genuineness $(F(2,136)$ $=16.45, p<.001, \eta^{2}=.20$ ), showing that the effect of source of data was even more pronounced for negative images. In other words, Croatian participants rated all images as being clearer and more genuine than the UK participants, but this difference was larger for negative images.

\section{Table 4}

Descriptive Statistics by the Valence of the Emotion

\begin{tabular}{lccc}
\hline & Negative & Neutral & Positive \\
\cline { 2 - 4 } & $M(S D)$ & $M(S D)$ & $M(S D)$ \\
\hline Intensity & $3.95(0.91)$ & $3.17(1.05)$ & $3.83(0.89)$ \\
Clarity & $3.99(0.94)$ & $3.13(1.10)$ & $3.87(0.96)$ \\
Genuineness & $3.97(1.00)$ & $3.67(1.04)$ & $4.11(0.91)$ \\
Strength of internal emotion & $3.15(1.10)$ & $2.87(1.09)$ & $3.44(1.09)$ \\
\hline
\end{tabular}




\section{Study 2}

\section{Method}

\section{Participants}

In Study 2, 422 mothers $(M=30.76$ years, $S D=4.54)$ and 106 fathers $(M=$ 32.53 years, $S D=5.53)$ of infants aged 1 to 12 months old $(M=6.53$ months, $S D=$ 3.25) participated. Almost all mothers and fathers were married (mothers: $98.8 \%$ and fathers: $100 \%$ ). The majority graduated from university or college (mothers: $74.5 \%$; fathers: $68.9 \%$ ), lived in a city with more than 100000 citizens (mothers: $46.3 \%$; fathers: $54.7 \%$ ) and perceived their income as average (mothers: $50.1 \%$; fathers: $50.0 \%)$. Also, around half of parents had one child (59.1\% of mothers and $62.3 \%$ of fathers), a quarter had two children (mothers: $27.7 \%$; fathers: $24.5 \%$ ), and $13.2 \%$ (of both mothers and fathers) had three children or more. A small minority of parents had twins in their last pregnancy (1.4\% of mothers; $1.9 \%$ for fathers).

\section{Instruments}

The City Infant Faces Database (CIFD; Webb et al., 2018) was used, as described in Study 1. Therefore, the same 139 black-and-white images were presented to the parents. However, to minimise the participant's burden, they rated only 20 photos each (more details in the Procedure section). In addition, participants needed to evaluate images only on one dimension - the expression of the image (negative, neutral, positive).

Demographic information was collected for: age, gender, marital status, education level, income, place of living (urban/rural), number of children, age of the youngest child and having twins in the last pregnancy.

\section{Procedure}

Data were collected online from May to October 2018. Participants gave their informed consent before entering the study. Snowball sampling was used to recruit possible participants. Two email links, one for mothers and one for fathers, were sent to private email addresses, shared via Facebook groups and web portals dedicated to parents. All images from the CIFD database were randomly distributed in seven blocks. Participants saw photos only from one of the blocks. Each participant rated 20 (blocks 1 -6) or 19 (block 7) images from the CIFD database. Each image was rated by at least 41 participants. Questions about the emotional expression of the image were presented below the image. Time was not limited. After completing the questionnaire, participants were provided with information on how accurate they were during the image evaluation. 


\section{Results}

The average percentage of agreement on the valence of the emotion presented on the image was $83.07 \%$ for mothers and $84.32 \%$ for fathers (Table 5). There was no significant difference in the average rate of agreement of valence of the image between mothers and fathers. However, in mothers, the rate of agreement was significantly lower for neutral images than for positive images $(74.56 \%$ vs. $91.27 \%$, $z=-2.14, p=.032$ ). Out of 139 images tested, 19 images had less than $75 \%$ agreement for both mothers and fathers; there were an additional eight images rated by mothers and seven images rated by fathers with less than $75 \%$ agreement. However, only four of these images had less than $75 \%$ agreement in both parents and students, so they are advised to be excluded in highly Caucasian samples (details on request from the corresponding author).

\section{Table 5}

Descriptive Statistics for the Level of Agreement by the Valence of the Facial Expression for Mothers and Fathers

\begin{tabular}{|c|c|c|c|c|c|}
\hline & \multicolumn{2}{|c|}{ Mothers $(n=422)$} & \multicolumn{2}{|c|}{ Fathers $(n=106)$} & \\
\hline Valence & $\begin{array}{l}\text { Agreement } \\
(\%)\end{array}$ & $\begin{array}{l}\text { No. images with } \\
<75 \% \text { agreement }\end{array}$ & $\begin{array}{l}\text { Agreement } \\
(\%)\end{array}$ & $\begin{array}{l}\text { No. images with } \\
<75 \% \text { agreement }\end{array}$ & $z$ \\
\hline $\begin{array}{l}\text { Negative } \\
(n=50)\end{array}$ & 80.16 & 11 & 79.39 & 14 & $\begin{array}{l}z=0.10 \\
p=.920\end{array}$ \\
\hline $\begin{array}{l}\text { Neutral } \\
(n=35)\end{array}$ & 74.56 & 13 & 78.59 & 10 & $\begin{array}{l}z=-0.40 \\
p=.689\end{array}$ \\
\hline $\begin{array}{l}\text { Positive } \\
(n=54)\end{array}$ & 91.27 & 3 & 92.61 & 2 & $\begin{array}{l}z=-0.26 \\
p=.795\end{array}$ \\
\hline Total & 83.07 & 27 images $^{\mathrm{a}}$ & 84.32 & 26 images $^{\mathrm{a}}$ & \\
\hline
\end{tabular}

Note. ${ }^{\text {a }}$ There is an overlap of 19 images with a level of agreement lower than $75 \%$ for both mothers and fathers. ${ }^{*} p<.05 ;{ }^{* *} p<.01$.

\section{Female versus Male Infants}

There was no difference in the level of agreement on the valence of the emotion (two-proportion $z$-test) in female versus male infants for negative $(z=0.60, p=.555)$, neutral $(z=0.53, p=.596)$, or positive valence $(z=0.37, p=.711)$ rated by mothers. The same was observed in fathers with no difference in agreement for negative $(z=$ $0.36, p=.719)$, neutral $(z=0.43, p=.667)$, or positive valence $(z=0.10, p=.920)$.

\section{Younger versus Older Infants}

There was no difference in the level of agreement on the valence of the emotion (two-proportion $z$-test) in younger versus older infants for negative $(z=0.59, p=$ 
$.555)$, neutral $(z=-0.15, p=.881)$, or positive valence $(z=-0.04, p=.968)$ rated by mothers or fathers (negative $(z=0.28, p=.780)$, neutral $(z=0.24, p=.810)$, positive valence $(z=-0.04, p=.968)$.

\section{First-Time versus Experienced Parents}

The agreement rate was examined according to the number of children parents had (one child vs. two or more children). Given that there were not enough fathers across both groups and the seven blocks of images, these analyses were conducted on mothers only. It was established that there was no significant difference in the rate of agreement (two-proportion $z$-test) between the first-time mothers and those who had two or more children for negative ( $81.75 \%$ vs. $79.58 ; z=0.28, p=.787)$, neutral (76.02\% vs. $75.33 \% ; z=0.07, p=.944)$, or positive images $(92.13 \%$ vs. $91.30 \%$; $z=0.16, p=.873)$.

\section{Comparison between the Samples}

Compared to UK data, the rate of agreement (two-proportion $z$-test) was equal for maternal ratings for neutral $(z=1.10, p=.276)$ and positive images $(z=0.97$, $p=.332)$ and paternal ratings for neutral $(z=0.69, p=.497)$ and positive images $(z=0.72, p=.478)$. There was no difference in the rate of agreement for valence of the facial emotional expressions between parents and students for negative, neutral, or positive images. However, compared to the original validation study in UK (Webb et al., 2018), the rate of agreement for negative images was significantly higher for UK raters than for Croatian mothers $(94.87 \%$ vs. $80.16 \%, z=2.29, p=.022)$ and fathers $(94.87 \%$ vs. $79.39 \%, z=2.38, p=.017)$.

\section{Discussion}

The CIFD (Webb et al., 2018) was developed as a research tool for examining the associations of perception of infant emotions and different outcomes, such as parental affective state and behaviour. It was tested in a sample comprising student midwives, student neonatal nurses, and members of the general public in the UK and was shown to be a useful tool. In the current study, we aimed to test the CIFD validity in a large sample of students and parents and check the cross-cultural validity of the CIFD. We found no differences in ratings between male and female infants or younger and older infants in both of our samples. We also found a high agreement for the valence of faces, as was found in the original validation study (Webb et al., 2018). These findings suggest that the CIFD is reliable and valid to use with parents and students and has cross-cultural validity. However, Croatian students rated the negative images as being clearer and more genuine than UK students, and the lower 
agreement rate for negative images in Croatian parents suggests further research is needed looking at cross-cultural differences for the negative images.

The fact that this study replicated results from a UK sample in a Croatian sample is an important finding. The location in which the UK study was carried out (London) is multi-culturally diverse. Over $22 \%$ of London inhabitants are from ethnic minority groups with a wide range of religious beliefs (Office for National Statistics, 2011). On the other hand, Croatia is predominantly Caucasian and Christian denomination (Croatian Bureau of Statistics, 2013). The cultural differences in these samples but overall consistency in the results support the cross-cultural validity of the CIFD.

However, cross-cultural validity needs further examination so conclusions are cautious at this stage. For example, a meta-analysis on cultural differences in emotion recognition suggested a so-called in-group advantage, i.e., higher accuracy when the members from the same cultural group are both expressing and perceiving emotions (Elfenbein \& Ambady, 2002). The fact that the infant's faces were provided by UK parents, only images of Caucasian babies were selected, and the high proportion of Caucasian people living in Croatia may have played a role in the high agreement across studies. Also, Croatian students rated images as more intense, clear, genuine, and provoked more intense internal emotions than UK raters. These differences might be due to Southern versus Northern differences in emotional expressiveness observed worldwide, especially in the Old-World countries (Pennebaker et al., 1996). Therefore, more research is needed in different cultures before the cross-cultural validity of the CIFD can be confirmed.

Several other differences arose in comparison to the initial validation in the UK. Namely, we found no differences in ratings between male and female infants and no difference between younger and older infants. In the original validation study, Webb et al. (2018) found more intense emotions for females and more genuine emotions for younger infants. Although these findings are interesting, there is inconsistency in the literature, especially concerning gender differences (Chaplin \& Aldao, 2013; Haley et al., 2006). Some studies show that female infants exhibit a broader array of emotional expressions and more intensive emotions, such as smiling and crying (Cossette et al., 1996; Fiamenghi, 2007; Sagi \& Hoffman, 1976), while others show that male infants show more joy, anger, fussiness and crying (Geangu et al., 2010; Weinberg et al., 1999). Regarding the infants' age, Volk et al. (2007) found that young infants' facial cues elicited stronger responses related to cuteness and adult parental care. Authors argued that this effect is a result of evolution since younger infants need more parental care.

Several instruments were administered to test the convergent validity of the CIFD, as a part of construct validity, including Troms $\varnothing$ Infant Faces (TIF) database and a set of questionnaires. The correlation for accuracy for the CIFD and TIF databases was low but significant. To prove high convergent validity, one would expect a high correlation between the two measurements (Carlson \& Herdman, 2012). However, the low correlation between the accuracy for CIFD and TIF 
obtained could be due to differences in the method of estimation. Namely, for CIFD, participants rated only the valence of the emotion (negative, neutral, or positive). In contrast, for the TIF, participants had to choose the exact emotion between the seven (happy, sad, disgust, fear, anger, surprise or neutral). Therefore, participants' estimation for TIF is far more specific than for CIFD. In comparison with CIFD, where the average agreement on the valence of the emotion of the image was $85.84 \%$, recognition of emotional expression for the TIF was much lower, with only $60.24 \%$. Supporting the use of a valence-based approach to rating emotions, research has found that adults tend to blend the expression for surprise and fear, and sadness and anger (Maack et al., 2017; Sullivan, 2018; Sullivan \& Lewis, 2003) when rating younger infants faces (under 12 months). This is further supported by a cross-cultural study where Camras et al. (2007) found a blending of fear and anger in infants. These mixed findings imply that recognising the valence, instead of a specific emotion, especially for very young infants, starting from a 1-month-old infant, might be more suitable and may further explain the low correlation between the CIFD and TIF.

Furthermore, higher recognition accuracy on the CIFD had a low but significant correlation with higher levels of empathy and lower levels of externally oriented thinking, as a part of alexithymia (Parker et al., 2003). This finding is in line with previous research that has found a lower level of accuracy in facial expression recognition in individuals who report higher levels of alexithymia (Parker et al., 1993). Thus, these associations of the CIFD with empathy and aspects of alexithymia suggest a moderate convergent validity of the CIFD. Furthermore, it was interesting that this pattern was observed for total accuracy on CIFD and negative and positive images, but not for neutral photos. These results are in line with findings that individuals with alexithymia show difficulties with automatic processing of angry faces (Vermeulen et al., 2006) and have a lower tendency to imitate negative facial expressions (Sonnby-Borgström, 2009). Finally, the non-significant correlation between accuracy for neutral images and measures of empathy and alexithymia may be due to a lower level of reliability of neutral photos found in the original validation study. Webb et al. (2018) examined whether participants would choose the same valence of emotions in retest situation four weeks later. Neutral images had the highest rate of change $(18.75 \%)$, meaning that initially neutral images, in retest situation, were rated as either positive or negative. Also, as a neutral facial expression does not express any specific emotion, it is possible that more empathetic individuals do not have a real advantage over individuals who are less empathetic in situations when there is no particular emotion.

We also expected accuracy on CIFD to correlate with identifying and describing emotions. However, this was not established for either of the two administered questionnaires that comprised these two aspects (ESCQ nor TAS-20). Therefore, these findings imply that self-reported identifying and describing emotions are not related per se to the accuracy of infant emotional expression recognition. Of different aspects of alexithymia, only externally oriented thinking was related to facial 
emotion recognition accuracy. This is similar to Prkachin et al.'s (2009) study, which found that externally oriented thinking was related to reduced capacity to detect facial expression, especially fear. This is also in line with the findings of a meta-analysis about the distinction between externally oriented thinking, a cognitive component that was more stable, and difficulty in identifying and describing feelings, as an emotional component of alexithymia, which were more state-dependent ( $\mathrm{Li}$ et al., 2015). However, individuals who describe themselves as being more empathetic and attending to their inner emotional states are more accurate in recognising negative and positive emotional expressions of infants, as described above. All in all, it is essential to note that, although the effect sizes are low, these correlations support the convergent validity of the CIFD, especially considering that these are two completely different methods of measuring other constructs, one relying on self-report and another being objective.

Our results showed no difference between mothers and fathers in accuracy of recognising the valence of infant facial expressions. This is not consistent with an older study that found females were more accurate and rapid than males in identifying infant facial expressions. This was not affected by previous experience with an infant (Babchuk et al., 1985). However, more recent studies support our results, finding no gender differences in infant face recognition (Arteche et al., 2016; Donadon et al., 2019; Maack et al., 2017; Proverbio et al., 2006). Furthermore, we found no difference in the accuracy recognition between non-parents (students) and parents. Also, we found no difference between first-time mothers and mothers with more children. This is consistent with Maack et al. (2017) who also found no difference in the judgment accuracy between parents and non-parents. However, it is contrary to the finding that parents show greater sensitivity to very sad infant faces than non-parents (Proverbio et al., 2006). Arteche et al. (2016) found that non-parents rate both happy and sad faces as more intense than parents, which the authors explained as the parents being exposed to a larger variety of infant faces intensity. These differences due to experience are substantiated with Izard et al.'s notion (1980) that training can help provide better accuracy, especially with training for negative emotions in participants (non-parents) who had low initial accuracy. Nishitani et al. (2011) found no differences in the accuracy rate between mothers and non-mothers in infant facial expression recognition. However, they found that the right prefrontal cortex (PFC) was more activated in mothers compared to non-mothers. Interestingly, this difference was not established for adult faces, implying that the right PFC may have an essential role in maternal behaviour. Furthermore, the previous study showed that mothers were more responsive to positive and negative infant expressions if it was their own infant rather than an unfamiliar infant (Barrett et al., 2012). However, we cannot relate the latter study to our findings, given that parents in our study evaluated only unfamiliar infant faces.

Several limitations of the study should be considered. First, although CIFD comprises both black-and-white images and coloured images, we tested only black- 
and-white images, so future studies on parents should validate coloured images, as well. However, it is worth mentioning that the advantage of black-and-white photos is a minimisation of perceptions of stimulus (e.g. skin tone, eye colour) that are not related to facial expressions (Arteche et al., 2016) and are rated as clearer than colour images (Webb et al., 2018), and thus could be more suitable for use. There were several differences in the methods of image presentation to the students' and the parents' samples. First, the CIFD was administered to students in a group, where they could first see the image on a projector screen and then fill out the questions on the paper form. On the other hand, the CIFD was administered individually to parents where they could see both the image and question on the screen simultaneously. Also, parents were told that they would receive immediate feedback on the accuracy, so perhaps they were more motivated than students who did not receive such feedback. Furthermore, students filled out all the questions regarding the image evaluation as in the original study. In contrast, parents filled out only the question on the valence of the image in order not to over-burden them. Also, the time necessary to rate each photo was not measured. This could provide additional information (such as presented in Maack et al., 2017), so future studies would benefit from ensuring reaction time is measured. This study did not include a second measurement point, so the test-retest reliability of CIFD could not be examined, and future research should look at this. Furthermore, future studies should be done with larger samples of fathers to test the possible effect of parental experience on the accuracy of recognition among first-time and experienced fathers. Also, future studies should test parental accuracy at recognising infant facial expressions as a prognostic indicator of parental sensitivity. A recent study did not find an association between recognition accuracy on CFID and self-reported parental responsiveness. However, it established that mothers with poor recognition of infant facial expression also reported poorer mother-infant bonding regarding lack of enjoyment and affection with the infant (Nakić Radoš, 2021). Nevertheless, there is some evidence that greater maternal sensitivity for positive and negative facial expressions may be associated with more positive maternal affect and behaviour during play (Donovan et al., 2007). This suggests that early maternal ability to recognise infant's faces is essential for infant survival and development and maternal behaviour during play with the infant and her affective states.

In conclusion, the findings of this study showed high agreement with the initial UK validation in both the students and parents' sample, except that agreement for negative images was lower for Croatian parents than in the UK study. Compared to the UK study, Croatian students rated images as more intense, clear, genuine, and reported stronger internal emotion. Furthermore, there was no difference in the accuracy between mothers and fathers or between first-time parents and experienced parents. Therefore, we recommend excluding four images from the database that reached low agreement across student and parent samples for Croatian samples. The CIFD is a promising tool for research that should be further validated in other 
countries, particularly in ethnically different or diverse populations, focusing on its predictive validity as a measure of parental sensitivity.

\section{References}

Arteche, A. X., Vivian, F. A., Dalpiaz, B. P. Y., \& Salvador-Silva, R. (2016). Effects of sex and parental status on the assessment of infant's faces. Psychology \& Neuroscience, 9(2), 176-187. https://doi.org/10.1037/h0101552

Babchuk, W. A., Hames, R. B., \& Thompson, R. A. (1985). Sex differences in the recognition of infant facial expressions of emotion: The primary caretaker hypothesis. Ethology \& Sociobiology, 6(2), 89-101. https://doi.org/10.1016/0162-3095(85)90002-0

Barrett, J., Wonch, K. E., Gonzalez, A., Ali, N., Steiner, M., Hall, G. B., \& Fleming, A. S. (2012). Maternal affect and quality of parenting experiences are related to amygdala response to infant faces. Social Neuroscience, 7(3), 252-268. https://doi.org/10.1080/ 17470919.2011.609907

Besel, L. D., \& Yuille, J. C. (2010). Individual differences in empathy: The role of facial expression recognition. Personality and Individual Differences, 49, 107-112. https://doi.org/10.1016/j.paid.2010.03.013

Bjorklund, D. F. (1997). The role of immaturity in human development. Psychological Bulletin, 122(2), 153-169. https://doi.org/10.1037/0033-2909.122.2.153

Bolzani-Dinehart, L. H., Messinger, D. S., Acosta, S. I., Cassel, T., Ambadar, Z., \& Cohn, J. (2005). Adult perceptions of positive and negative infant emotional expressions. Infancy, 8, 279-303. https://doi.org/10.1207/s15327078in0803_5

Camras, L. A., Oster, H., Bakeman, R., Meng, Z., Ujiie, T., \& Campos, J. J. (2007). Do infants show distinct negative facial expressions for fear and anger? Emotional expression in 11 months old European American, Chinese, and Japanese infants. Infancy, 11(2), 131155. https://doi.org/10.1111/j.1532-7078.2007.tb00219.x

Carlson, K. D., \& Herdman, A. O. (2012). Understanding the impact of convergent validity on research results. Organizational Research Methods, 15(1), 17-32. https://doi.org/10. $1177 / 1094428110392383$

Castanho A, P., \& Otta, E. (1999). Decoding spontaneous and posed smiles of children who are visually impaired and sighted. Journal of Visual Impairment and Blindness, 93, 659662. https://doi.org/10.1037/a0014037

Chaplin, T. M., \& Aldao, A. (2013). Gender differences in emotion expression in children: A meta-analytic review. Psychological Bulletin, 139(4), 735-765. https://doi.org/10. 1037/a0030737

Cheng, G., Zhang, D. J., Guan, Y. S., \& Chen, Y. H. (2015). Preliminary establishment of the standardised Chinese infant facial expression of emotion. Chinese Mental Health Journal, 29(6), 406-412. https://psycnet.apa.org/record/2015-30813-002 
Cossette, L., Pomerleau, A., Malcuit, G., \& Kaczorowski, J. (1996). Emotional expressions of female and male infants in a social and a nonsocial context. Sex Roles, 35, 693-709. https://doi.org/10.1007/bf01544087

Croatian Bureau of Statistics. (2013). Census of population, households and dwellings, 2011: Population of citizenship, ethnicity, religion and mother tongue. Croatian Bureau of Statistics.

Darwin, C. (1872). The expression of emotion in man and animals. Oxford University Press.

Davis, M. H. (1983). Empathic concern and the muscular dystrophy telethon. Personality and Social Psychology Bulletin, 9(2), 223-229. https://doi.org/10.1177/0146167283092005

Donadon, M. F., Martin-Santos, R., \& Osório, F. L. (2019). Baby Faces: Development and psychometric study of a stimuli set based on babies' emotions. Journal of Neuroscience Methods, 311, 178-185. https://doi.org/10.1016/j.jneumeth.2018.10.021

Donges, U. S., Kersting, A., \& Suslow, T. (2014). Alexithymia and perception of emotional information: A review of experimental psychological findings. Universitas Psychologica, 13(2), 745-756. https://doi.org/10.11144/Javeriana.UPSY13-2.apei

Donovan, W., Leavitt, L., Taylor, N., \& Broder, J. (2007). Maternal sensitivity, mother-infant 9-month interaction, infant attachment status: Predictor of mother-toddler interaction at 24 months. Infant Behavior Development, 30(2), 336-352. https://doi.org/10.1016/j. infbeh.2006.10.002

Ekman, P. (1972). Universals and cultural differences in facial expressions of emotion. In J. Cole (Ed.), Nebraska Symposium on Motivation, 1971 (Vol. 19, pp. 207-282). University of Nebraska Press.

Ekman, P., \& Friesen, W. V. (1971). Constants across cultures in the face and emotion. Journal of Personality and Social Psychology, 17, 124-129. https://doi.org/10.1037/ h0030377

Ekman, P., \& Friesen, W. (1976). Pictures of facial affect. Consulting Psychologists.

Ekman, P., Friesen, W. V., O’Sullivan, M., Diacoyanni-Tarlatzis, I., Krause, R., Pitcarin, T., Ricci-Bitti, P. E., Scherer, K., Tomita, M., \& Tzavaras, A. (1987). Universals and cultural differences in the judgments of facial expressions of emotion. Personality Process and Individual Differences, 54(4), 712-717. https://doi.org/10.1037//00223514.53.4.712

Elfenbein, H. A., \& Ambady, N. (2002). On the universality and cultural specificity of emotion recognition: A meta-analysis. Psychological Bulletin, 128(2), 203-235. https://doi.org/10.1037/0033-2909.128.2.203

Fahmy, H. A., Fahmy, S. F., García, A. A. D. B., \& Juan, G. B. (2020). Emotion detection in infants using an ensemble classifier with a novel member selection technique. Proceedings of the 2020 Summer Simulation Conference, 18, 1-9.

Fiamenghi, G. A (2007). Emotional expression in infants' interactions with their mirror images: An exploratory study. Journal of Reproductive and Infant Psychology, 25, 152160. https://doi.org/10.1080/02646830701292365 
Geangu, E., Benga, O., Stahl, D., \& Striano, T. (2010). Contagious crying beyond the first days of life. Infant Behavior and Development, 33, 279-288. https://doi.org/10.1016/j. infbeh.2010.03.004

Gery, I., Miljkovitch, R., Berthoz, S., \& Soussignan, R. (2009). Empathy and recognition of facial expressions of emotion in sex offenders, non-sex offenders and normal controls. Psychiatry Research, 165(3), 252-262. https://doi.org/10.1016/j.psychres.2007.11.006

Haley, D. W., Handmaker, N. S., \& Lowe, J. (2006). Infant stress reactivity and prenatal alcohol exposure. Alcoholism: Clinical and Experimental Research, 30(12), 20552064. https://doi.org/10.1111/j.1530-0277.2006.00251.x

Izard, C. E. (1971). The face of emotion. Appleton-Century-Crofts

Izard, C. E. (1994). Innate and universal facial expressions: Evidence from developmental and cross-cultural research. Psychological Bulletin, 115(2), 288-299. https://doi.org/10.1037/0033-2909.115.2.288

Izard, C. E., Huebner, R. R., Risser, D., \& Dougherty, L. M. (1980). The young infant's ability to produce discrete emotion expressions. Developmental Psychology, 16(2), 132-140. https://doi.org/10.1037/0012-1649.16.2.132

Lane, R. D., Lee, S., Reidel, R., Weldon, V., Kaszniak, A., \& Schwartz, G. E. (1996). Impaired verbal and nonverbal emotion recognition in alexithymia. Psychosomatic Medicine, 58(3), 203-210. https://doi.org/10.1097/00006842-199605000-00002

Li, S., Zhang, B., Guo, Y., \& Zhang, J. (2015). The association between alexithymia as assessed by the 20 -item Toronto Alexithymia Scale and depression: A meta-analysis. Psychiatry Research, 227(1), 1-9. doi:10.1016/j.psychres.2015.02.006

Maack, J. K., Bohne, A., Nordahl, D., Livsdatter, L., Lindahl, Å. A., Øvervoll, M., Wang, C. E. A., \& Pfuhl, G. (2017). The Tromso Infant Faces Database (TIF): Development, validation and application to assess parenting experience on clarity and intensity ratings. Frontiers in Psychology, 8, 1-13. https://doi.org/10.3389/fpsyg.2017.00409

McDonald, P. W., \& Prkachin, K. M. (1990). The expression and perception of facial emotion in alexithymia: A pilot study. Psychosomatic Medicine, 52(2), 199-210. https://doi.org/10.1097/00006842-199003000-00007

Montagu, A. (1961). Neonatal and infant immaturity in man. JAMA, 178(1), 56-57. https://doi.org/10.1001/jama.1961.73040400014011

Nakić Radoš, S. (2021). Parental sensitivity and responsiveness as mediators between postpartum mental health and bonding in mothers and fathers. Frontiers in Psychiatry, 12, 723418. https://doi.org/10.3389/fpsyt.2021.723418

Nishitani, S., Doi, H., Koyama, A., \& Shinohara, K. (2011). Differential prefrontal response to infant facial emotions in mothers compared with non-mothers. Neuroscience Research, 70(2), 183-188. https://doi.org/10.1016/j.neures.2011.02.007

Office for National Statistics. (2011). 2011 Census. Retrieved from: https://www.ons.gov.uk/ census/2011census 
Parker, J. D., Taylor, G. J., \& Bagby, R. M. (1993). Alexithymia and the recognition of facial expression of emotion. Psychotherapy and Psychosomatics, 59, 197-202. https://doi.org/10.1159/000288664

Parker, J. D., Taylor, G. J., \& Bagby, R. M. (2003). The 20-Item Toronto Alexithymia Scale: III. Reliability and factorial validity in a community population. Journal of Psychosomatic Research, 55(3), 269-275. https://doi.org/10.1016/s0022-3999(02)00578-0

Pearson, R. M., Cooper, R. M., Penton-Voak, I. S., Lightman, S. L., \& Evans, J. (2010). Depressive symptoms in early pregnancy disrupt attentional processing of infant emotion. Psychological Medicine, 40, 621-631. https://doi.org/10.1017/ S0033291709990961

Pennebaker, J. W., Rimé, B., \& Blankenship, V. E. (1996). Stereotypes of emotional expressiveness of Northerners and Southerners: A cross-cultural test of Montesquieu's hypotheses. Journal of Personality and Social Psychology, 70(2), 372-380. https://doi.org/10.1037/0022-3514.70.2.372

Prkachin, G. C., Casey, C., \& Prkachin, K. M. (2009). Alexithymia and perception of facial expressions of emotion. Personality and Individual Differences, 46(4), 412-417. https://doi.org/10.1016/j.paid.2008.11.010

Proverbio, A. M., Brignone, V., Matarazzo, S., Del Zotto, M., \& Zani, A. (2006). Gender and parental status affect the visual cortical response to infant facial expression. Neuropsychologia, 44(14), 2987-2999. https://doi.org/10.1016/j.neuropsychologia. 2006.06.015

Raboteg-Šarić, Z. (2002). E - upitnik: Skala emocionalne empatije i skala mašte [EQuestionnaire: Emotional Empathy Scale and Fantasy Scale]. In K. Lacković-Grgin, A. Proroković, V. Ćubela, \& Z. Penezić (Eds.) Zbirka psihologijskih skala i upitnika, Svezak 1 [Collection of psychological scales and questionnaires, Vol. 1] (pp. 44-49). Filozofski fakultet u Zadru.

Reissland, N., Francis, B., \& Mason, J. (2013). Can healthy fetuses show facial expressions of "pain" or "distress"? PLOS ONE 8(6), e65530. https://doi.org/10.1371/journal. pone. 0065530

Sagi, A., \& Hoffman, M. L. (1976). Empathic distress in the newborn. Developmental Psychology, 12, 175-176. doi:10.1037/0012-1649.12.2.175.

Sonnby-Borgström, M. (2009). Alexithymia as related to facial imitation, mentalisation, empathy, and internal working models-of-self and-others. Neuropsychoanalysis, 11(1), 111-128. https://doi.org/10.1080/15294145.2009.10773602

Sullivan, M. W. (2018). Anger, sad, and blended expressions to contingency disruption in young infants. Developmental Psychobiology, 60(8), 938-949. https://doi.org/10.1002/ dev. 21768

Sullivan, M. W., \& Lewis, M. (2003). Emotional expressions of young infants and children: A practitioner's primer. Infants \& Young Children, 16(2), 120-142. 
Takšić, V., Mohorić, T., \& Duran, M. (2009). Emotional Skills and Competence Questionnaire (ESCQ) as a self-report measure of emotional intelligence. Psihološka obzorja, 18(3), 7-21.

Takšić, V., Mohorić, T., \& Munjas, R. (2006). Emocionalna inteligencija: Teorija, operacionalizacija, primjena i povezanost $\mathrm{s}$ pozitivnom psihologijom [Emotional intelligence: Theory, operationalization, application and relation with positive psychology]. Društvena istraživanja: Časopis za opća društvena pitanja, 15, 729-752.

Tang, W., Bao, C., Xu, L., Zhu, J., Feng, W., Zhang, W., Lin, C., Chen, L., Cheng, Q., Ding, P., Zhou, M., Bao, Y., Yu, X., Zhao, K., \& He, J. (2019). Depressive symptoms in late pregnancy disrupt attentional processing of negative-positive emotion: An eyemovement study. Frontiers in Psychiatry, 10, 780. https://doi.org/10.3389/fpsyt. 2019.00780

Taylor, G. J., Bagby, R. M., \& Parker, J. D. (1991). The alexithymia construct: A potential paradigm for psychosomatic medicine. Psychosomatics 32, 153-164.

Vermeulen, N., Luminet, O., \& Corneille, O. (2006). Alexithymia and the automatic processing of affective information: Evidence from the affective priming paradigm. Cognition and Emotion, 20(1), 64-91. https://doi.org/10.1080/02699930500304654

Volk, A. A., Lukjanczuk, J. L., \& Quinsey, V. L. (2007). Perceptions of child facial cues as a function of child age. Evolutionary Psychology, 5(4), 801-814. https://doi.org/10.1177/ 147470490700500409

Webb, R., \& Ayers, S. (2019). Postnatal mental health and mothers' processing of infant emotion: An eye-tracking study. Anxiety, Stress, \& Coping, 32(5), 484-497. https://doi.org/10.1080/10615806.2019.1620215

Webb, R., Ayers, S., \& Endress, A. (2018). The City Infant Faces Database: A validated set of infant facial expressions. Behavior Research Methods, 50(1), 151-159. https://doi.org/10.3758/s13428-017-0859-9

Weinberg, M. K., Tronick, E. Z., Cohn, J. F., \& Olson, K. L. (1999). Gender differences in emotional expressivity and self-regulation during early infancy. Developmental Psychology, 35, 175-188. https://doi.org/10.1037/0012-1649.35.1.175

Yan, F., Dai, S. Y., Akther, N., Kuno, A., Yanagihara, T., \& Hata, T. (2006). Fourdimensional sonographic assessment of fetal facial expression early in the third trimester. International Journal of Gynecology \& Obstetrics, 94(2), 108-113. https://doi.org/10.1016/j.ijgo.2006.05.004 


\title{
Validacija Baze dojenačkih lica City na uzorku studenata i roditelja
}

\begin{abstract}
Sažetak
Baza dojenačkih lica City (engl. City Infant Faces Database, CIFD; Webb i sur., 2018) sadržava 154 slike emocionalnih ekspresija dojenčadi koje se mogu koristiti u eksperimentalnim istraživanjima dojenačke facijalne komunikacije, prepoznavanja facijalne ekspresije i roditeljske osjetljivosti. CIFD je validiran samo na malome uzorku iz opće populacije i na studentima primaljstva i sestrinstva u Ujedinjenome Kraljevstvu (UK). Stoga je cilj ovoga istraživanja bio validacija baze na većemu uzorku hrvatskih studenata te roditelja dojenčadi u dobi od 1 do 12 mjeseci. Tristo pedeset studenata (Istraživanje 1) te 422 majke i 106 očeva (Istraživanje 2) gledali su slike dojenačkih lica bijele rase. Studenti su procjenjivali slike iz CIFD-a i Baze dojenačkih lica Tromsø. Također su ispunili upitnike koji mjere empatiju, aleksitimiju te prepoznavanje i ekspresiju emocija. Roditelji su procjenjivali valenciju facijalnih ekspresija slika iz CIFD-a. Rezultati i kod studenata i kod roditelja u skladu su s inicijalnom validacijom, osim što je slaganje za negativne ekspresije niže kod hrvatskih roditelja nego u istraživanju provedenome u UK-u. U usporedbi s istraživanjem provedenim u UK-u studenti su procjenjivali slike kao intenzivnije, jasnije i autentičnije te su kod njih izazivale snažnije emocije. Nadalje, nije bilo razlike u točnosti između majki i očeva ili između onih koji su roditelji prvi put i onih koji su iskusni roditelji. Stoga možemo zaključiti da je CIFD obećavajući instrument za istraživačke svrhe te bi ga trebalo dalje validirati u drugim državama, usmjeravajući se pritom na njegovu prediktivnu valjanost.
\end{abstract}

Ključne riječi: dojenče, facijalna ekspresija, validacija, baza, roditelji

Primljeno: 14. 7.2021. 